\title{
INSTANTE Y MOMENTO OPORTUNO \\ EN LOS GRAFOS EXISTENCIALES DE \\ CHARLES S. PEIRCE. \\ POR UNA DIMENSIÓN KAIROLÓGICA \\ DE LA CREATIVIDAD
}

\author{
JOSÉ ROMERO TENORIO \\ Institut ACTE \\ Centre National de la Recherche Scientifique (CNRS-Paris)
}

\begin{abstract}
RESUMEN.Para la estética, la creatividad es la emergencia del instante que la vuelve irrepetible o un transitar pendular que la hace resurgir como reminiscencia cegada por un ocaso repetitivo. Haciendo coincidir proceso y teleología (pensamiento al que nos dirigimos), Peirce aglutina estas dos dimensiones (instante y tránsito), sin atisbar realmente un atisbo de humanidad para disfrutar de lo ínfimo. De ahí que propongamos un momento oportuno que nos dirija hacia una temporalidad más humana.
\end{abstract}

PALABRAS CLAVE: Kairos, creatividad, Grafos Existenciales, instante.

\section{Instant and opportune time in Existential Graphs of Charles S. Peirce. For a Kairologic dimension of creativity}

ABSTRACT. For esthetics, creativity is the emergence of the moment that makes it unique or a pendulum movement that revives as reminiscent blinded by a repetitive sunset. Matching process and teleology (thought which we turn), Peirce join these two dimensions (time and transit), without really glimpse a moment of humanity to enjoy the negligible. Hence, we propose an opportune time to direct us towards a more human temporality.

KEY WORDS: Kairos, creativity, Existential Graphs, instant.

\section{INTRODUCCIÓN}

En este artículo presentamos algunos aspectos mollares de una investigación sobre la creatividad en la improvisación de jazz, realizada en el seno de la Unité Mixte de Recherche 8218 «Arts, Créations, Théories et Esthétique» del Centre National de la Recherche Scientifique (CNRS) y de la Université Paris 1 Panthéon-Sorbonne ${ }^{1}$.

Asumimos el reto de utilizar los Grafos Existenciales del filósofo norteamericano Charles S. Peirce como herramienta de análisis, con una premisa fundamental: la improvisación es una pieza musical que carece de partitura y su desarrollo, como comprobamos, está supeditado a lo que denominamos lógica del rebote. El saxo comienza y el bajo le responde, simplemente. Y así se suceden en el tiempo, uno a otro.

1 La investigación aprobada y financiada por el CNRS se titula «Étude de la plasticité dans la dynamique peircienne autour des Graphes Existentiels». 
Los grafos, de alguna manera, llevan imbricados en su extraño ADN estos dos principios: ausencia de patrón y rebote.

Podría sonar paradójico el hecho de que definamos los grafos como escritura de la nada (Romero Tenorio, 2012:146), más cuando es palpable la escrupulosa sistematicidad con la que Peirce despliega su implante gráfico en estratos, símbolos y reglas de paso de una a otra capa.

Esta obsesión taxonómica, desde nuestro punto de vista, no busca asentar un sistema lógico que explique en términos universales las relaciones entre preposiciones, tal como plantea Roberts (1992), Pietarinen (2005) o Sowa (2013). Este último no percibe el impulso revolucionario de los ensayos cosmológicos de los años 90 del siglo XIX en el pensamiento de Peirce, como sí hiciera Short, para quien las hipótesis de Peirce sobre el caos original del universo le hicieron desistir de apoyarse en las tesis estadísticas para explicar la evolución de las leyes (Short, 2010). Contrariamente a Short, Sowa percibe una perfecta continuidad entre las investigaciones lógicas peirceanas de la década de los 70 y 80 del siglo XIX y los grafos, que aparecieron 10 años después. Para el autor americano, las «ligaduras de líneas conectadas de identidad colocan toda proposición en el plano de posibilidad, de tal manera que si analizamos "Es un perro o un gato", los grafos existenciales, como cuantificadores universales, expresarían: "Si hay algo, luego es un perro o un gato"» (Sowa, 2013).

La taxonomía detallada de elementos y planos de incidencia entre proposiciones buscan, paradójicamente, la implantación de una a-sistematicidad en el orden lógico de las cosas. Pero no nos confundamos: no es un ejercicio de deconstrucción ni de razonamiento lógico sobre relaciones existentes.

En este sentido los planteamientos de un filósofo más contemporáneo a nosotros como Deleuze sobre la construcción rizomática (Deleuze, 1969) de la realidad, al lado de los de Peirce, parecerían conservadores. El autor americano, un siglo antes que el filósofo francés, acuña el término endoporéurico (Pietarinen 2013) para referirse a la pura motilidad (Romero Tenorio, 2012) de los grafos que remontan el cauce del fenómeno; el cual, constituyéndose en una estructura arbolea, a medida que se despliega pragmáticamente, adquiere existencia.

No implican por tanto la búsqueda de un grado cero de la escritura o del pensamiento, pero sí de su anatomía danzante constituyente. En este sentido Peirce define los grafos como «moving picture of thought» (CP.4.8, 1906), las imágenes en movimiento del pensamiento (Pietarinen, 2011).

Por otro lado, equipara completamente el pensamiento con su posibilidad de ser inscrito en una superficie material (Ms501, 1911), estableciendo la equidistancia del logos con respecto a sus dos acepciones, palabra y pensamiento.

Por esta vía, poniendo en relación inscribilidad y pensamiento, Peirce lanza una teoría de la cognición sumamente original. Si el pensamiento puede ser inscrito o, dicho de una manera wittgenstiana (Tractatus 4.014): si existe una relación interna (Anderson, 1987:125) entre escritura y pensamiento, no hay argumento para apuntalar el hecho de que el espíritu o las operaciones mentales preceden a la escritura. 
Es cierto que la escritura nos enseñó a razonar por conceptos, a estructurar la realidad por paquetes: una palabra que existe corresponde a una cosa existente (Foucault, 1966). La práctica de la escritura nos hace percibir el mundo como algo compuesto por entidades ontológicamente existentes que se excluyen: la mente con respecto a la materia, la realidad con respecto a la ficción.

Evidentemente podemos dibujar un dedo en un cartel y situarlo en un camino para indicar la salida. Ese mismo dedo puede representar la unidad. Pero no es que exista primero la idea mental de contar o señalar y después el uso de instrumentos empíricos como el dedo o este mismo dibujado en el cartel.

La visión que trasciende los grafos es que es la operación concreta, en nuestro caso las prácticas de contar o de señalar, son las que iconizándose, inscribiéndose, rebotan hacia atrás, hacen las veces de espejo y reflejan así una imagen mental en el operador y en el receptor de esas praxis.

\section{Ausencia}

Los grafos trazan un itinerario en las relaciones existenciales y no existentes: un fenómeno adquiere por tanto existencia a medida que se despliega por saltos abductivos: el dedo de la mano salta a nuestra mente, y después al cartel, que, sacudiéndolo, llena de sentido el camino en el cual nos perdemos. Nada aún consolidado semánticamente. Los grafos reconstituyen esta fisiología oscilatoria del pensamiento ${ }^{2}$.

De ahí esas líneas, cortes, coronas que masacran al grafo rompiendo su corporalidad y llevándola a una especie de espacio extradiegético, como vemos en este grafo (Romero Tenorio, 2014:175):

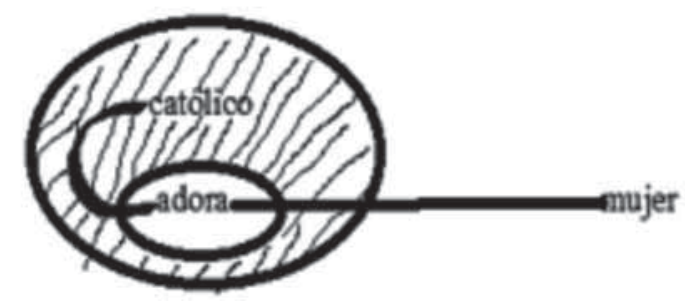

Estos signos no ofrecen ninguna información ni establecen relaciones lógicas entre los elementos. Los concebimos como puras acciones gestuales que atraviesan el cuerpo gráfico hasta su desmaterialización en la teridentidad (Romero Tenorio, 2014:178), es decir, en una exterioridad lisa, sin rupturas, «lo que permite ir más allá de este cuerpo gráfico en una fisicidad extrema dispuesta a ser observada» (Romero Tenorio, 2012:308).

2 Peirce define los grafos en términos de corporalidad: «fisiología del razonamiento deductivo» (Ms500, 1911) 
Esta fisicidad no coincide con el cuerpo gráfico, sino lo transciende. El procedimiento lógico descrito por Sowa concibe un grafo como un cuerpo inerte en la cual está ya presente una serie de recorridos lógicos posibles. El grafo se limitaría a desplazar, al plano de posibilidad, relaciones lógicas ya existentes.

El observador se acercaría al grafo como si fuera un cuerpo que en una fría cama de metal esperase una autopsia. Este procedimiento supone un desmembramiento complejo del grafo en cuanto sistema de diferencias funcionales a través de las cuales se constituyen y se fijan los polos. Una autopsia implica la disección del cuerpo gráfico en un estado de rigor mortis por los mapas definitorios de funciones establecidas por el orden lógico. Por el contrario, un grafo es «una imagen en movimiento del pensamiento» que se caracteriza por su disponibilidad a un desmembramiento siempre reiterado, ya que es en éste donde el grafo vive regenerándose continuamente. El corte del grafo no es nunca una última vez, una línea que nos hará entender, de forma permanente, un razonamiento planteado en una premisa.

Este desmembramiento no supone una autopsia con cortes penetrantes que romperá la continuidad del cuerpo gráfico, sino una irradiación pluri-orientada que atraviesa y recorre una posibilidad nunca enteramente colmada.

Que no nos quepa duda que esta irradiación se solidificará en significados semánticamente constituidos, en un último corte, incluso en manifestaciones tan carentes de sentido como una improvisación jazzística. Pero eso no sucede en la génesis del proceso, como defiende Pietarinen (2013), ni tampoco al final; aquí radica la complejidad temporal del desplegarse del pensamiento sobre la que los grafos intentan arrojar luz: ¿acaso cuando el músico comienza a tocar rompe el silencio?

Debemos, sin embargo, partir de la base de que la improvisación es una obra que es una ausencia de obra: los artistas ofrecen siempre de nuevo al público una nota carente de un significado teleológico, una hoja en blanco. Por ello podríamos decir que constituye «una presentación antes que una representación» (Bergman, 2007:62). Las notas salen de los instrumentos como burbujas de jabón que contienen el vacío que les hace levitar y, en un instante inescrutable, ese mismo vacío rompe en pedazos esa membrana en la cual se refleja todo su entorno. Desaparecen en el transitar, como el singular mimbre en los cruces que derivarán en una silla.

Llevando hacia adelante su performance, arrancando (ab-ducere) a la nada sentidos transitorios, el músico experimenta una cierta libertad, a la cual atribuimos un profundo valor ético, en cuanto no se siente enteramente coartado por la práctica de la música.

A la inversa, recorriendo (agò) hacia atrás (gogé) esa misma cuerda de equilibristas, es decir, en la retroducción (apagogé), esa performance suturará un sentido, aunque sea la negación del mismo.

Esta paradoja se convierte en la sístole y diástole del pensamiento peirceano, que podríamos simplificar en la siguiente cuestión: ¿Cómo puede emerger lo nuevo, lo creativo, si sólo podemos aprehender aquello de lo cual ya teníamos algún conocimiento? 
Aunque parezca que a primera vista incida en el aspecto cognitivo de la creatividad (Chauviré, 2008:33), esta reflexión tiene mucho más que ver con la esfera fenomenológica de la aparición en el mundo del fenómeno en su visibilidad ontológica (De Tienne, 2004:15).

En nuestro trabajo de investigación, resolvimos ese bucle estableciendo el rebote como instancia originaria creativa, coincidiendo en parte con la doctrina falibilista epicúrea de Peirce, que, desde nuestro punto de vista, corresponde con una concepción ética del tránsito. Podríamos expresar sucintamente esta visión de la siguiente manera: puesto que es imposible lo absolutamente nuevo, conformémonos con recrearnos en el proceso de creación.

En este movimiento circular, el hombre, desde nuestro punto de vista, no puede encontrar el momento oportuno para la creatividad, ya que ése está compuesto por una serie de instantes irrepetibles que señala simplemente el momento caótico en que fulgura el fenómeno, como la marca de tiza en el universo-signo representado por la pizarra, como veremos.

Trataremos de entender cómo el hombre puede experimentar esa distancia que predispone a esa apertura distraída en la cual regurgite ese tiempo oportuno que suspende la secuencia cronológica lógica. Así se experimenta la irrupción de la discontinuidad, generando un tránsito hacia una nueva forma de vida, desde que el hombre pueda disponer en dicho momento, ya no de una ocasión que le permita una segunda oportunidad, sino de la ocasión de una oportunidad que le abra la posibilidad de acceder al favor de una temporalidad más humana, por contar en cada momento con la brevedad y fugacidad del tiempo. De modo que en la estrecha apertura que descubre en el favor de esta brecha temporal, pueda regocijarse de lo íntimo, de lo pequeño, de lo poco.

\section{CONTAMINACIONES Y DERRAMAMIENTOS COMO LÓGICA ESTÉTICA CREATIVA EN LOS Grafos Existenciales}

Los grafos, concebido por Peirce en «la etapa de su vida intelectual más creativa» (Colapietro, 2007:33), reflejan ante todo una imaginación visual potente. El patrón que guía la construcción de los grafos no es ni lógico ni matemático, sino ante todo estético. La idea de que las conexiones entre los signos se dén más por balances cromáticos, texturas armonizadas y contaminaciones cromáticas que por relaciones conceptuales o lógicas demuestra que la creatividad emerge por las tensiones estéticas entre los signos (Zalamea, 2011).

Peirce, sin embargo, no concibe un mundo de signos completamente cortado de la real experiencia de los discursos que palpita en el diálogo concreto entre los seres humanos y su semiosfera (Lotman, 1996). Para ello establece una serie de disposiciones fundamentales, es decir, hábitos, que el hombre debe adquirir con el fin de que sus acciones sean lo más coherentes y racionales posibles. Esta solidificación no significa que sean «defendibles a la larga», ni muchísimo menos que «las proposiciones verdaderas sean irrebatibles» (Hookway, 2002:65). 
Simplemente estos hábitos contribuyen a la logicidad de nuestro estar en el mundo, no por un supuesto realista como aproximación hacia un estado de imperturbabilidad de las creencias por parte de las evidencias (Hookway, 2011), sino por una serie de principios éticos: «la fe, esperanza y caridad, que, según San Pablo, son los dones espirituales más elevados» (CP.2.655, 1878).

Las tensiones estéticas se resuelven en la plasticidad del espíritu (mind) del hombre, que en cuanto glassy essence (CP.6.238, 1893), esencia vítrea, recubre las palabras, las cosas y al propio hombre y les hace participar de un espíritu común que crece por los inagotables y continuos vericuetos de la posibilidad. Por consecuencia, como demuestra Kauffman, la causa final de la cual habla Peirce no orienta estas tensiones hacia la consecución de formas concretas, sino a la propensión a la actualización de potencialidades (Kauffman, 2009). Por ello, «cada vez que se actualiza un potencial, hay una actualidad que se potencializa» (Andrade, 2011:196).

Subiendo otro peldaño en nuestro análisis, estas tensiones estéticas no conectan ni potencian los pensamientos por relaciones lógicas; por el contrario, generan texturas en el pensamiento-signo (Tiercelin, 1998) en la cual el hombre opera, contribuyendo al desarrollo de su cartografía experiencial, donde las diferentes dimensiones se conectan por derramamientos cromáticos y granulaciones sin perder continuidad.

Los grafos son por tanto táctiles: con la punta de los dedos sentimos sus texturas y las incisiones, lo serrado de las coronas y el rastro sedoso en el papel dejado por los colores. Más que a pensar relaciones lógicas, Peirce nos induce a sentir, a entender la plasticidad del pensamiento y su entronque con el mundo por sintonizaciones esenciales. Es ahí donde Peirce introduce dos conceptos extraños: musement (Barrena, 1996:31) y ágape (Castañares, 2008).

Con el primero, Peirce sugiere que el universo no es para entenderlo, «sino para degustarlo» (CP.6.458, 1908), para sentirlo agradable, para dejarse maravillar desde la distracción del puro juego.

El ágape es una sintonización esencial, inexplicable y que se potencia a través de la praxis. De ahí la tercera ley del espíritu, que dicta que «una idea que ha excitado a otra posee una creciente tendencia a excitarla» (Ms961, 1892). El gato encontrará más placer en perseguir a los ratones en la medida en que persiga ratones. El músico, lo mismo. La creación es recreación y no tanto acción orientada hacia un fin, según la perspectiva de Peirce.

¿Pero cómo puede emerger la creatividad en esta recreación?

Según Zalamea:

«en los bordes de la contradicción, desde fondos obscuros, mediante tachones y reescrituras, a través de intentos mixtos y no claramente orientados, en suma, desde el lodazal, emerge la creación» (Zalamea, 2011:93).

El autor colombiano remite a una lógica claramente topográfica donde se puede «ubicar muy diversas instancias de creatividad e imaginación» (Zalamea, 2011:83). La creatividad surge por tanto de una serie de tensiones estéticas entre los signos en el «horos (borde) con el cual (...) se puede llegar a completar 
faneroscópicamente, por vez primera en la historia de la filosofía, la ubicua díada análisis/síntesis» (Zalamea, 2011:89).

Para nosotros, no es suficiente para que emerja la creatividad el hecho de estar sumergidos en el «lodazal», decantarlo analíticamente y manipularlo. Concebimos el horos en término de borde temporal y no topológico, como Havenel (2010) defiende: es un, cada vez genuino cronotopo (Bakhtine, 1988) dialógico donde emerge la creatividad a través de relaciones puramente existenciales.

Es decir, no es tan importante para encontrar «esos momentos privilegiados de la consciencia» (Zalamea, 2011:80) hallarse sumergido en el lodazal como abrir al tránsito ese horos para que no nos ahogue en la premura del instante que busque salir de ese lodazal. De este modo podremos discernir sus dos orillas ajustando la amplitud de lo lejano en la estrecha apertura de lo cercano y así actuar con la prontitud de una resolución creativa que rechace cualquier vacilación.

\section{LA LÓGICA DEL UNIVERSO: LA PIZARRA Y LA TIZA}

El grafo restituye esa oscilación trascendental que evita ese instante repentino que invade el presente acrónico, no permitiendo avistar al final una huella de la plenitud intempestiva del tiempo desde el cual reencontrarnos con el summum bonum (CP.2.116, 1902) estético, en cuanto «forma profunda de razonabilidad (...) y evolución continua de la potencialidad» (Zalamea, 2011:83).

Para entender esta lógica pendular del tiempo, nos remitimos a un ensayo cosmológico de Peirce titulado The Logic of Universe (1898).

Imaginemos, como el autor americano, que el universo es una pizarra en blanco:

"Considerad la pizarra como una especie de diagrama de la original y vaga potencialidad o, en todo caso, como un cierto estadio de su determinación» (CP.6.203,1898).

Esta pizarra sin marca es evidentemente un símbolo de la vaguedadcontinuidad original. Este «magnífico conjunto» (CP.6.197, 1898) es el lugar de toda diferencia, de toda dimensión, de toda definición posible: un Nada-Todo originario: «no se perciben puntos en la pizarra; no existen dimensiones en el continuum».

La pizarra es la hoja en blanco sobre la cual los grafos se inscriben ${ }^{3}$, un «Sheet of Assertion» (CP.4.537, 1906) que representa el cosmos; la pizarra es análoga a cualquier universo: al del silencio que espera que la música la colonice, al del libro que el lector se sumerja.

Pero ese silencio no va antes de la música: como la pizarra, es esa materia primera que constituye «el sustrato invisible de la potencialidad, razón por la cual carecía de toda propiedad y función distinta a la de asegurar la continuidad y la realidad del cambio sustancial» (Mc Mullin, 2010:22).

3 Para profundizar en el concepto de «hoja en blanco», véase: Romero Tenorio 2014. 
Peirce continúa:

«En este momento, trazo sobre la pizarra una línea con una tiza. Tal discontinuidad es uno de esos actos brutos a través de los cuales la indistinción originaría habría podido dar un paso hacia la definición» (CP.6.203, 1898).

Este primer gesto, esta primera respuesta ofrecida por la práctica sígnica, constituye el premier corte, el primer zarpazo propinado a la piel del mundo. Podríamos decir que es el momento en el que el músico comienza a tocar y rompe el silencio de la hoja en blanco, produciendo una discontinuidad que no es tal. Ya que ésta es uno de estos actos decisivos que sancionan la existencia de un hecho y determina su temporalidad histórica. Este primer gesto es la primera fractura, el primer arañazo al continuo, que manifiesta la esencia y al mismo tiempo, la nulidad existencial. Si la «original vagueness» (CP.6.203, 1898) era una unidad indiferenciada de la totalidad, en esta unidad y por esta unidad, se instaura una determinación que reconoce su nada efectual.

Expliquemos estas ideas con un ejemplo. Tenemos en nuestras manos, como Peirce, un «libro de hojas separadas» (CP.4.512, 1898). El libro está compuesto por un lomo, la portada, la contraportada, las hojas, un marca-libro por donde coletean miles de palabras como peces en las redes de un pescador. Mi lectura comienza y terminan el lomo, la portada, la contraportada, las hojas, el marcalibro y las palabras escapan de las redes. Todo se vuelve un "magnífico conjunto» (CP.6.197, 1898). En la praxis, en la acción de lectura, el libro se transforma en una hoja en blanco que el pasar de páginas no puede discretizar. Permanezco en ese espacio ideal de lectura, del cual nunca he dejado de pertenecer. Por ello en la determinación pragmática reconozco la nada efectual del libro: lo poseo desposeyéndolo de su materialidad (hojas, portada, etc.), a través de relaciones puramente existenciales. No es una desposesión intencional, sino un transitar en la práctica, en el pensamiento-acción, en el pensamiento-signo.

Nos preguntamos si este transitar por las páginas del libro sin encallar en los arrecifes de palabras restituye a nuestra experiencia ese presente acrónico en el cual podemos encontrar, para empezar, ese momento oportuno en el cual recrearnos en la lectura o si, la marca de tiza, por el contrario, emerge como instante que oscurece el resto del mundo en esa nada efectual, eliminando cualquier posibilidad de transformación del hombre o apertura hacia lo nuevo.

En lo que llama Peirce, filosofía elíptica, «el curso temporal del universo, si bien tiene una fuerza que lo impulsa hacia algo, termina por regresar al mismo punto de su origen» (Kalil, 2011:37). El tránsito, en este sistema que Peirce llama epicureísmo, se produce entre dos puntos inexistentes:

«El punto de inicio y el punto de llegada no son ideales. El movimiento de la naturaleza se aleja de un no-punto y avanza hacia otro no-punto; él da piruetas de posición en posición» (CP.6.582, 1905).

Este punto de origen es la nada, el horos, el borde, entendido como cronotopo «endoporeutic» (CP.4.561, 1906); esto es, como un espacio-tiempo 
exclusivamente vinculado (endon) a su propio transitar (poros), a su existencia fenomenológica. Constituye un punto eterno de giro y, por tanto, desata el momento culminante de la madurez del tiempo: un momento subversivo, carente de instantes, de presencia absoluta de una temporalidad ajena al propio destino humano en cuanto tejido vítreo que se resuelve en el «long run» (CP.1.67, 1893) del pensamiento-signo.

Lejos de oscurecer el universo, este movimiento, que da piruetas, arroja luz, una visibilidad ontológica (De Tienne, 2004:15) sobre el hombre mismo, capaz de sacrificar sus propias metas individuale ${ }^{4}$ en pro de ese conjunto de prácticas interpretantes solidarias que mantendrán viva «la antorcha de la verdad» (CP.1.339, 1875). De esta manera puede tener la oportunidad de experimentar una vida combatiente y un tiempo subversivo, sin el apresuramiento del instante ajeno a la dimensión ética humana, teniendo opciones de esta manera de apresar la ocasión propicia en el momento oportuno y decisivo.

Peirce no nombra, a esta filosofía elíptica, epicúrea, por casualidad: la ética epicúrea es ante todo una ética del falibilismo y del tránsito 5 . Pero, ¿tránsito hacia dónde? Parece que establezca un eterno retorno al mismo punto; pero este punto no existe, es «un no-punto». Esto es, una existencia fenomenológica temporal rigurosamente circunscrita a su emergencia pragmática.

\section{KaIROLOGÍA CONTRA INSTANTE}

Sólo en este transitar en la práctica, el hombre puede experimentar un momento oportuno alejado del tiempo cronológico de su aparecer en el acaecer reiterativo de su destino. En este transitar el hombre formula un conocimiento a-histórico fundado sobre la no existencia de experiencias previas que no recaliente el mismo eje (McLuhan, 1996:43) por donde transcurre su destino. El hombre que mapea racionalmente evidencia su des(a)tino por no contar con el momento oportuno, por no saber inscribir en la acción el propio kairós, por no saber entrar en la acción en el momento oportuno. Por ello es desolado por el desgaste de su eje unívoco de acción, azotado por el rozamiento de una novedad que se presenta siempre acaecida y de un «siempre» que aparece cada vez novedoso transfiriéndose en nuevos soportes, contextos y circunstancias.

Viendo la marca de tiza sobre la pizarra podemos pespuntear la continuidad de un orden que debe ser producido de nuevo y, sin embargo, se marca con jaboncillo el lugar por donde la aguja se puede volver hacia atrás después de cada punto sign(ad)o, para meter la hebra o el hilo en el mismo sitio por

\footnotetext{
4 De ahí que Peirce sitúe a la caridad como uno de los principios fundamentales en los cuales se debe basar la lógica.

5 Para una explicación más profunda sobre la influencia de la ética epicúrea en PeIRcE, véase RoMERo TENORIO 2012.
} 
donde pasó antes. De esta manera, desde nuestro punto de vista, la acción se desintoniza con respecto a un presente en cuya contemporaneidad lo ya acaecido y lo que está por suceder aparecen incorporados y entrecruzados, perdiéndose así el tránsito entre ellos.

«Efectivamente, ambos momentos se experimentan gracias a la circularidad de repeticiones y retornos que abarca toda praxis actual, perdiendo elasticidad la musculatura temporal del presente por una elongación patológica hacia un futuro quimérico y, al mismo tiempo, por una contracción a causa de un eterno retorno hacia un pasado mitificado» (Popper, 2010).

Es esa marca de jaboncillo sobre el tejido vital del presente la que produce una tracción isométrica que bloquea el tránsito temporal. Esa «marca», como la dejada por la tiza en la pizarra, constituye el signo de la primera inferencia ofrecida en respuesta al mundo. Producía una línea que separaba y al mismo tiempo decidía sobre el curso del continuum universal de la pizarra. La línea arrancaba a la nada un sentido resituándola en la materialidad de la incisión gráfica, transfiriéndolo a ese lugar de potencialidad a partir del cual se decidía la realidad en su carácter fluctuante y transitorio: «es para el blanco de la tiza la segundeidad activa del negro y, para el negro, la segundeidad activa del blanco» (CP.6.203, 1898).

Por el contrario, advierte Peirce, la línea es a su manera continua:

«Sin embargo, existe un cierto elemento de continuidad en esta línea. ¿De dónde proviene? Éste no es más que la originaria continuidad de la pizarra que vuelve continuo todo aquello inscrito en la pizarra» (CP.6.203, 1898).

Quebrando la totalidad de la pizarra, la línea muestra de pertenecer a ella. La línea marcaba el lugar de su propia emergencia y, al mismo tiempo, la nada que sostiene todas sus transformaciones. No existe la línea de tiza de un lado y la pizarra del otro (de la misma manera que no existe el silencio y la música que lo rompe en dos polos diferenciados): existe el signo de la pizarra, que es «un sentimiento de nada». La línea está en efecto inscrita sobre una superficie temporal homogénea cuyo propio evento es su continuidad. La línea participa del entero que la ha generado. $\mathrm{O}$, lo que es lo mismo, indica este entero como aquello propio del cual ella hace parte, al cual corresponde. Manifiesta la mismidad que les aglutina.

La línea de tiza es la pizarra, pizarra donde empero intervino el acto de definición, la primera respuesta interpretante que, interponiendo una distancia, puede reconocerse y decir: «hete aquí una línea de la pizarra». El signo indica, señala la continuidad de la cual proviene el propio signo. En ésa, el signo se manifiesta como una totalidad signada.

Pero, «¿de dónde proviene esta continuidad» — se pregunta Peirce. «De nada que no sea esa original vagueness»- se responde a sí mismo. Original vagueness que no es ni más ni menos que la nada absoluta. Por tanto, el signo es una nada en cuanto indica la mismidad que le constituye, que le hace un Todo, pero a la cual el signo puede solamente corresponder a partir de la distancia intercalada entre el instante de su aparición y el lugar en el cual emerge, en su hic et nunc. 
En este cronotopo complejo emerge la eventualidad de toda posible definición, de todo posible tránsito. Es un espacio-tiempo «horótico» (Zalamea, 2010), "transuasado» ${ }^{6}$ (CP. 2.89, 1902), en el cual no existe ni pizarra ni marca de tiza, solamente un signo, un «mark» constitutivo.

Podríamos decir que es esta distancia entre el ser y la nada la que restituye a la traza la temporalidad en la cual puede emerger más allá de esa extraña nostalgia del futuro que bloquea su carácter transitorio. De este modo siempre es posible un nuevo inicio y un nuevo tiempo, una nueva traza sin sucumbir abruptamente a la singularización del instante que impida una mirada prospectiva y retrospectiva de su estar en el mundo.

Asfixiado por el tiempo de la consciencia que diluye el presente en una extraña miscelánea de sueños, pasado y futuro, un cruce repentino con otro tren abre la brecha en la musculatura de la memoria vacía del instante devastador a Eugene Gant, protagonista de la novela de Thomas Wolfe, Of Time and the River, permitiendo ese tránsito que pendulariza la experiencia abriéndola a su horos temporal:

"Y se miraron unos a otros durante un momento, pasaron y se desvanecieron y desaparecieron para siempre; sin embargo, le parecía que había conocido a esas personas, que las conocía mejor que a los pasajeros de su propio tren y que, tras haberlas visto durante un instante bajo cielos inmensos y temporales, mientas se precipitaban a través del continente hacia mil destinos distintos, se habían rozado, pasado, desvanecido, pero recordarían esto para siempre. Y pensó que la gente de los dos trenes también sentía esto: se adelantaban lentamente unos a otros y sus bocas sonreían y sus miradas se mostraban amistosas, pero le parecía que había cierta pena y aflicción en lo que sentían. Puesto que, tras haber vivido juntos como extraños en la inmensa y hormigueante ciudad, ahora se habían encontrado sobre la tierra eterna, se habían abalanzado para pasarse mutuamente durante un momento entre dos puntos del tiempo sobre los brillantes rieles, y nunca más volver a encontrarse, hablarse, conocerse, y la brevedad de sus días, el destino del hombre, fue en ese instante saludo y despedida» (Wolfe, 1971:473).

Eugene yace casi inerte en el vagón de un tren que compite con otro rival en una vertiginosa carrera, mientras que a su alrededor todo ocurre en una asfixiante inmovilidad: los pasajeros hablan entre sí, se cruzan, toman café «como extraños en la inmensa y hormigueante ciudad». Ese ambiente de la belle époque que desfila en su tren es como el río: necesariamente desembocará y morirá en el mar. Cada conversación, cruce o mirada se desvanecerán una vez agoten su temporalidad.

Así, el momento oportuno nunca llega y, en la simple recepción nostálgica de la acción presente, actúa siempre a destiempo, con lo cual esquiva, sin disposición a actuar (o sin hábito como diría Peirce) y sin resistencia alguna (sin secondness y, por tanto, sin distancia que permite el tránsito), el desafío kairológico.

6 Según Peirce, significa «traducción. transacción, transfusión, transcendental» (CP. $2.89,1902)$ 
Sin embargo, Eugene se sumerge, al observar los viajeros del otro tren en el instante del cruce, en un monólogo interior que hace que todo ese suceder lineal chorree y se entremezcle como los lamparones en una paleta. Encallados en su interior como en una piedra (metáfora que Wolfe usa en contraposición a la hoja, que muere en la tierra como el río en el meandro), el flujo de pensamientos le da la posibilidad de retornar al origen (como el tren que siempre puede volver a la estación desde donde parte), de dialogar, de encontrarse «sobre la tierra eterna (...) entre dos puntos del tiempo sobre los brillantes rieles».

En otra novela de Thomas Wolfe, Look Homeward, Angel, Eugene cruza en un tren una ciudad, quedando todo paralizado, como fotogramas de una película en una bovina tirada en el rincón de una fría cabina de proyección. Eugene experimenta, respecto a ese universo ínfimo congelado, la misma distancia que el cirujano al cuerpo de su paciente, según la comparación realizada por Walter Benjamin entre el cirujano y el mago. Éste mantiene la distancia natural entre él mismo y su paciente "pero la reduce con su autoridad»; mientras que el cirujano «procede a la inversa»: achica la distancia con el paciente penetrando en el interior con sus manos «y la incrementa sólo un poco en virtud del cuidado con que su mano se mueve entre los órganos» (Benjamin, 2003:80).

En ese instante decisivo, en el cual el espacio-tiempo se desestructura con respecto a su andamio envigado, la experiencia fugaz del hic et nunc se convierte en una especie de cubo de Rubik, cuyas piezas, como órganos de un cuerpo que no se deja recomponer en su unidad funcional, las arma y las rearma con una mirada analítica y a la vez distraída. Eugene renuncia a situarse ante ese paisaje y, en lugar de ello, como un cirujano, «se introduce operativamente en él» (Benjamin, 2003:80). Así, la fuente de la plaza se paraliza y Gant cree estar contemplando una fotografía suya de hace años y que la muerte arriba tras las sombras de la realidad.

Esta paradoja, esta desestabilización del tiempo lineal le permite competir contra el tiempo y vencerlo, en cuanto puede comprar un billete de vuelta, volver hacia atrás, entender las mismas cosas (yendo por la misma vía), regresar a la misma escena congelada, pero de otra manera: «Sin la estructura esencial del tiempo. Fijado en un no-tiempo (...) sin un momento de transición» (Wolfe, 1997:157).

Atravesando de esta manera el tiempo, éste se queda suspendido en la coniza del instante, en el intersticio de las líneas de fuga que construyen el paisaje de la plaza, hasta el punto en el cual estas líneas convergen en un instante donde ninguna forma es posible, sólo el inicio de una evanescencia. Esta temporalidad elíptica se delinea como tendencia a la supresión de la temporalidad y como ejercicio de reapropiación de esta misma temporalidad en la insuprimibilidad; ejercicio equilibrista, que suspende el impulso unificador del tiempo sobre el abismo de la transmutación de sus momentos, y se queda en la línea de separación (en el instante) en la cual esa temporalidad es generada. 


\section{Momento oportuno y creatividad. El diálogo entre el Grafista y el Grafeus}

La creatividad supone saber inscribir en la acción, que surge en esa temporalidad pendular, el propio kairós, en entrar en la acción en el momento oportuno. Y este momento oportuno, decía Aristóteles, no es dado por la inteligencia, ya que no es una elección a priori; por ello produce un efecto en el pensamiento ajeno a todo propósito unificador y regulador:

«Si lo hubiera sabido el acreedor habría ido a determinado lugar cuando su deudor estaba recibiendo allí un dinero; pero, aunque no fue con ese propósito, por accidente recuperó su dinero cuando llegó a ese lugar. Y, aunque suela frecuentarlo, lo que ocurrió no fue por necesidad ni porque así suceda en la mayoría de los casos. El fin, recuperar lo que se le debe, no es una de las causas presentes en él, sino un objeto de elección y un resultado del pensamiento; se dice entonces que fue allí fortuitamente. Pero si por elección y con tal propósito hubiese ido a ese lugar, recuperando su dinero siempre o la mayoría de las veces, en tal caso no se podría hablar de un hecho fortuito. Vemos entonces que la suerte es una causa accidental que concurre en las cosas que se hacen para algo y que son objeto de elección. Por eso el pensamiento y la suerte se refieren a un mismo orden, ya que no hay elección sin pensamiento» (Aristóteles, 1995:63).

El tyché, la casualidad del momento oportuno, supone una elección no inteligente, en el sentido aristotélico: no posee ni surge de una regularidad. Sin embargo, concierne al pensamiento, ya que produce un efecto antes y más allá de la volición. Por ello, Aristóteles afirma que:

«las causas de lo que sucede como resultado de la suerte son, pues, necesariamente indeterminadas. De ahí que se piense que la suerte es algo indeterminado o inescrutable para el hombre, pero también se puede pensar que nada sucede debido a la suerte» (Aristóteles, 1995:63).

Aristóteles diferencia dos modos de actividad mental: la inteligencia, caracterizada por la regularidad; y el pensamiento, por la acción, por el efecto que se produce en la mente del actor o de los actores.

El hombre recuperó su dinero «sin haber ido con ese propósito» (purpose). Pero encontró el momento oportuno, que no tiene que ser el más idóneo. De ahí que la tyché se produzca sobre un fondo de indeterminación inescrutable para el hombre a partir del cual es posible restituir a la temporalidad su carácter puramente transitorio. El más oportuno hubiera sido, dice Aristóteles, fruto de la elección inteligente del acreedor: el momento en el cual el deudor recibe su salario. Pero se encontró con él en la plaza cuando había ido para ver un espectáculo, comprar en el mercado u otro propósito. Por consiguiente, recuperar lo debido fue al fin al cabo una elección dada por esa coyuntura. $\mathrm{Y}$ puesto que ha producido un efecto en la mente del actor ajeno a una intencionalidad precisa, esta acción se integra con el fluir del pensamiento.

El acreedor llegó a la plaza en el momento oportuno; el contrabajista entra en la sinfonía en el momento justo; el grafista responde al grafeus cuando se 
debe. Siempre puede haber mejores momentos para la creación o para cobrar deudas, sin duda elegidos volitivamente. Lanzarse al tyché no siempre es fácil y supone, entre otras cosas, renunciar a privilegios.

Estamos en el Jazz Cafè Milano y asistimos a la improvisación de dos músicos. Podemos estar de acuerdo que producen música, e incluso, que tenían el propósito de producirla, pero no de crear algo preciso. Pero la clave no es solamente el propósito, sino el procedimiento. Es más, en la improvisación, como en los grafos, procedimiento y propósito coinciden, en su proyecto teleológico. Pensamos que esta perspectiva es la adecuada para abordar el lenguaje plástico y creativo de los grafos existenciales.

Peirce imagina un universo en perenne creación donde dos figuras se expresan fabricando signos o introduciendo modificaciones en el propio grafo: el grafista y el grafeus. El grafeus es como el contrabajista en una improvisación de jazz: es el que genera un cierto ambiente, con sonidos penetrantes y atmosféricos pero limitados en su capacidad de articulación, por la densidad de las notas. No rasga las cuerdas, sino como ganchos, los dedos las agarran por detrás y desollan las notas de las cuerdas, que parecen que quisieran permanecer adheridas como lapas a las peñas. El grafista, sin embargo, es más ágil; como un trompetista, únicamente tiene que mover las falanges para producir sonidos; conecta su impulso (drift) creador directamente con el propio acto de crear. De ahí que el grafista es la figura que introduce modificaciones:

«Si el procedimiento del grafeus se funda sobre la continuidad de la creación, el del grafista lo hace sobre la sucesión de modificaciones. A medida que el proceso avanza, es decir, es pensado, adquiere «being», existencia, «entire determinateness». Pero solamente en la realización última del acto de creación, el universo adquirirá existencia, es decir, plena determinación en el sentido que nada vacile en la indeterminación» (CP.4.431, 1906).

¿Pero cómo produce el grafista estas modificaciones? Nos dice Peirce que el grafista es un «mind-reader» (CP.4.431, 1906). Como siempre, nos tenemos que preguntar por la elección de los términos que usa Peirce. Dice que lee el espíritu del grafeus, y no su pensamiento. El grafista se conecta al espíritu del grafeus y no trata de entender el pensamiento lógico que cartografía su procedimiento. Se produce por tanto una especie de sintonización esencial, de tal manera que el grafista puede adivinar su intención, conocer parcial o totalmente la obra del grafeus, una vez que concluya "pero no llegará a conocer su proceso de realización» (CP.4.431, 1906), ya que es una pura improvisación.

Defendemos que lo que Peirce llama scribing, para referirse al proceso de incidir grafos, es una escritura esencialmente tijista, lo cual no quiere decir que no cauterice de alguna manera el sentido. De ahí que el filósofo americano nos advierta de que al final el universo siempre adquirirá plena determinación, de la misma manera que la improvisación terminará siendo una composición musical.

Lo importante, como hemos advertido, es que el procedimiento coincida con el propósito. El patrón que guía al scribing, a la escritura gráfica, como a la improvisación en jazz, no es una partitura o patrón perfectamente definidos, 
sino el propio scribing, la propia performance. Es una partitura que se va creando en el acto de tocar el instrumento, de realizar incisiones gráficas sobre una hoja en blanco.

No se trata, sin embargo, de una escritura que pretenda deconstruir nuestros discursos lógicos, sino más bien es un acto que se concentra en «la puntualidad de la experiencia que fluye en el hic et nunc»(Romero Tenorio, 2014:187). El scribing no persigue destruir las partituras, los mapas que nos orientan en el mundo, sino que los abandonemos. De esta manera, no se bloquea el sentido, sino se reabre a una polifonía dialógica, donde se puede escrutar el carácter fluctuante de los contenidos, el universo de posibilidades en el cual están inscritos.

Este carácter fluctuante encuentra reflejo en uno de los símbolos más herméticos del implante gráfico peirceano: el anillo serrado (saw-rim)." (CP $4.529,1903)$.

Interpretar un grafo es la acción más esencial y simple que se puede realizar. Sólo hace falta observar y olvidarse de las piruetas conceptuales con las que quieren despistarnos los circuitos de sentido. Partiendo de la observación más simple del saw-rim, nos damos cuenta de que lo esfumado de su contorno representa estas fluctuaciones de los contenidos, y que su borde quebrado, como un serrucho, abre surcos hacia lo posible (Romero Tenorio, 2014:184). El scribing se impone como una frontera pendular entre procedimiento y propósito, entre la sección alfa y gamma de los grafos. Ambos se con-funden y se con-forman en la propia acción. De esta manera:

«los grafos no se reducen a una taxonomía de símbolos que organizan el intercambio de información; son una malla de signos que no termina nunca de revelarse en sus infinitos pliegues y repliegues, jalonados por inagotables despliegues posturales. Siendo pura motilidad, los grafos no se dejan reproducir ni crean correspondencias lineales entre las palabras y las cosas. Permaneciendo siempre temblorosos en sus arquetipos iniciales, (representado por lo serrado y esfumado del anillo que estrangula toda expresión), los grafos tienen que ver con un mapa que ha de ser producido, construido, siempre conectable, alterable, con múltiples entradas y salidas, con sus líneas de fuga» (Romero Tenorio, 2014:184).

Aquí entra en juego una serie de temas centrales en la obra de Peirce: el falibilismo, el sinejismo (continuidad), el tijismo, la posibilidad, la creatividad, etc. Pero lo que nos interesa es reflexionar sobre el elemento que aglutina, como si de un pegamento se tratase, todo el sistema: y este elemento no es espacial, topológico, como piensa Zalamea (2010); sino temporal, puramente kairológico.

Centrémonos en las acciones del grafeus y del grafista, del contrabajista y del trompetista. El grafeus es el «creador del universo y propulsor de su desarrollo cuya esencia depende de la continuidad del acto creativo». El grafista es un «intérprete que manipula, modifica, aporta incisos cuya esencia depende de la sucesión de actos manipulativos» (CP.4.431, 1906).

¿Quién realiza primeramente incisiones? ¿Quién inicia la performance? ¿Quién rompe el silencio de la hoja en blanco? 
En un acto de reduccionismo, podríamos aseverar que el grafeus comienza, ya que asegura la continuidad y, después, llega el grafista para aportar incisos y abrir nuevas posibilidades. Pero no es así, ya que ellos están, desde el inicio, en un diálogo esencial y constitutivo. Ellos se constituyen en la acción que frecuentan. No podemos fijar un comienzo y un momento sucesivo en la acción de grabar signos. De la misma manera, no podemos establecer una experiencia absoluta del silencio y de la música que lo rompe, como dos momentos separados de la misma acción. No podemos percibir el silencio sino en su ruptura y en su encuentro con la música; y paralelamente, no sentimos la música sino en función del silencio que se abre como la hoja en blanco y se deja romper.

La hoja en blanco es una ubicuidad silenciosamente habitada por quien la inscribe, una simple ocasión para la creatividad, para la incisión. En ella reside el niño que dibuja con su lápiz y, por no avistar los márgenes, ensucia el parquet. En ella nos alojamos los lectores que transitamos por el libro sin accidentarnos en sus páginas; tanto el niño como nosotros experimentamos esa misma sucesión rítmica de silencios y palabras, de trazos y vacíos que experimentan el grafeus y el grafista.

El acople, la intersección de estas experiencias en la continuidad palpitante de la práctica no la establece el topos de la propia hoja en blanco, sino el horos de lo oportuno del momento, el kairós. ¿A quién no le ha sucedido que las páginas de un mismo libro pesen más o menos dependiendo del momento de la lectura? Incluso el sentido de la creatividad de una performance puede variar en función del instante en el cual interviene el músico. Puede modificar la composición entrando en un momento u otro en la performance o simplemente apretando con más energía los botones de la trompeta.

TABLA DE ABREVIATURAS DE LA BIBLIOGRAFÍA PEIRCEANA

CP C.S. Peirce (1931-1958): Collected Papers vol. 1-8, C. Hartshorne, P. Weiss, A.W. Burks (eds), Cambridge: Harvard University Press

Ms Microfilms de los Manuscritos de C.S. Peirce (1967), conservados en Houghton Library (Harvard). Citados según la numeración de R.S. Robin, Annotated Catalogue of the Papers of Charles S. Peirce, Amherst: University of Massachusetts Press.

BibLIOGRAFíA

Andrade, Eugenio (2011). «La vigencia de la metafísica evolucionista de Peirce». Cuaderno de Sistemática Peirceana vol. 3, pp.175-219.

ARIstóteles (1995). Física. Madrid: Gredos.

BaKhtine Mijail (1988). L'autore e l'eroe. Teoria letteraria e scienze umane. Torino, Einaudi.

BarRena, SARa (1996). "Introducción, Traducción y notas a Un Argumento Olvidado en favor de la Realidad de Dios» (en línea). www.unav.es/gep/Barrena/Sara.pdf, último acceso 20 de mayo del 2015. 
Benjamin, Walter (2003). La obra de arte en la época de su reproductividad técnica. México: Ítaca.

Bergman, Mats (2007). «Representationism and Presentationism». Transactions of the Charles S. Peirce vol. 43, n.1, pp.53-89.

Castañares, Wenceslao (2008). «El acto creativo: Continuidad, innovación y creación de hábitos». Utopía y Praxis Latinoamericana vol.13 n.40.

Chauviré, Christiane (2008). L'OEil mathématique: Essai sur la philosophie mathématique de Peirce. Paris: Kimé.

Colapietro, Vincent (2007). "Peirce's Rhetorical Turn». Transactions of the Charles S. Peirce Society vol. 43 n.1, pp.16-52.

Deleuze, Gilles (1969). Logique du sens. Paris: Les Éditions de Minuit.

De Tienne, André (2004). «Is Phaneroscopy as a Pre-Semiotic Science Possible?». Semiotiche vol. 2 n.4, pp.15-29.

Foucault, Michel (1966). Les mots et les choses. Une archéologie des sciences humaines. Paris: Gallimard.

Girel, Matthias (2003). «The Metaphysics and Logics of Psychology: Peirce's Reading of James's Principles». Transactions of the Charles S. Peirce Society vol. 39 n. 2, pp. 163-204.

Havenel, Jérôme (2010). «Peirce’s Topological Concepts», en: M. E. Moore (ed.), New Essays on Peirce's Mathematical Philosophy. Illinois: Open Court, pp. 283-321.

HOOKWAY, CHRISTOPHER:

—, (2011). "Peirce’s Strategies for Proving Pragmatism» (en línea). www.cspeirce.com/ menu/library/aboutcsp/hookway/strategies.doc, último acceso 20 de mayo del 2015.

—, (2002). Truth, Rationality, and Pragmatism. Oxford: Clarendon Press, 2002.

Kalil, Richard (2011). «Sobre la geometría del tiempo de Peirce. La metafísica del absoluto». Cuaderno de Sistemática Peirceana vol. 3, pp. 5-52.

Kauffman, Stuart. «Towards a Post Reductionist Science: The Open Universe» (en línea. http://arxiv.org/PS_cache/arxiv/pdf/0907/0907.2492v1.pdf, último acceso 20 de mayo del 2015.

Lotman, Iuri (1996). Semiosfera I. Semiótica de la cultura y del texto. Valencia: Fronesis Cátedra.

Mcluhan, Marshall (1996). Comprender los medios de comunicación. Barcelona: Paidós.

McMuldin, ERNAN (2010). "From matter to materialism ... and (almost) back», en: P. Davies, N. H. Gregersen (eds.), Information and the Nature of Reality. Cambridge: Cambridge University Press, pp. 13-37.

Pietarinen, Ahti-Veikko:

—, (2013). «Moving Pictures of Thought II: Graphs, Games, and Pragmaticism's Proofs» (en línea). http://www.helsinki.fi/ pietarin/publications/Semiotica-Diagrams-Pietarinen.pdf, último acceso 20 de mayo del 2015.

—, (2011). «Moving pictures of thought II». Semiotica 186:1-4, 315-331.

—, (2005). «Compositionality, Relevance and Peirce's Logic of Existential Graphs». Axiomathes 15, 513-540.

Popper, Karl (2010). La sociedad abierta y sus enemigos. Barcelona: Paidós

Roberts, Don D. (1992). «The Existential Graphs». Computers Math. Aplic. vol.23 n.6-9, pp.639-663.

Romero Tenorio, José Manuel:

—, (2014). «Escritura de una aporía. Tránsitos y obstrucciones en los Grafos Existenciales de Charles S. Peirce». Pensamiento vol.70 n.262, pp.171-191. 
—, (2012). "Étude de la plasticité dans la dynamique Peircienne autours des Graphes Existentiels de Charles S. Peirce». Thèse de Doctorat, Paris: Université de Paris 1 Panthéon-Sorbonne.

Short, Thomas L. (2010). «Did Peirce Have a Cosmology?». Transactions of the Charles S. Peirce Society 46 (4), pp. 521-543.

Sowa, JoHn:

—, (2013). «From Existential Graphs to Conceptual Graphs» (en línea). http://www. jfsowa.com/pubs/eg2cg.pdf, último acceso 20 de mayo del 2015.

—, (2011). «Peirce's Tutorial on Existential Graphs». Semiotica, 186:1-4, 345-394.

Tiercelin, Claudine (1998). La pensée-signe. Études sur C.S. Peirce. Paris: Jacqueline Chambon.

Wittgenstein, Ludwig (2007). Tractatus Logico-Philosophicus. Madrid: Tecnos.

Wolfe, ThOMAS:

-, (1997). Look Homeward, Angel. New York: Simon and Schuster.

-, (1971). Del tiempo y del río. Barcelona: Montesinos.

Zalamea, Fernando:

-, (2011). «Creatividad y plasticidad en el Logic Notebook». Cuaderno de Sistemática Peirceana vol. 3, pp. 79-103.

-, (2010). Los Gráficos Existenciales Peirceanos. Sistemas de Lógicas Diagramáticas del continuo: Horosis, Tránsitos, reflejos. Bogotá: Fondos, Universidad Nacional de Colombia.

Institut ACTE

José Romero TENORIO

Centre National de la Recherche Scientifique

(CNRS-Paris)

joserotenorio@yahoo.es

[Artículo aprobado para publicación en diciembre de 2016] 